LA JUDICIABILIDAD DE LAS CUESTIONES ELECTORALES EN EL SISTEMA INTERAMERICANO

GERMÁN J. BIDART CAMPOS

Universidad de Buenos Aires 

Revista de Derecho Político, núm. 34, 1991, pp. 371-376

\title{
LA JUDICIABILIDAD DE LAS CUESTIONES ELECTORALES EN EL SISTEMA INTERAMERICANO
}

\author{
POR \\ GERMÁN J. BIDART CAMPOS \\ Universidad de Buenos Aires
}

Vamos a proponer una tesis que para algunos sistemas electorales de países que son parte en la Convención Americana sobre Derechos Humanos (Pacto de San José de Costa Rica) puede resultar un poco audaz. Esa tesis consiste en postular que, en torno de los artículos 8,23 , y 25, las cuestiones electorales deben contar con control jurisdiccional suficiente.

¿Por qué así? El argumento se nos vuelve sencillo en su razonamiento. Vamos a desarrollarlo.

El artículo 23 del Pacto de San José reconoce los derechos políticos, cuyo enunciado despliega en el acápite 1 en tres incisos. Es un diagrama mínimo que sirve como eje. El proceso electoral y el derecho electoral activo y pasivo están contenidos en él.

Desde ya conectamos con este eje mínimo de derechos políticos a los partidos políticos en la instancia electoral. Lo hacemos aunque en el citado artículo 23 no venga dada alusión alguna a ellos, porque entendemos que la realidad político-constitucional contemporánea en todo el mundo, y por ende en nuestros sistemas americanos, así como el ideal de justicia, no conocen el desenvolvimiento efectivo de los derechos políticos sin un sistema de partidos.

Por otra parte, el artículo 16 del Pacto, que debe comprenderse en relación con todos los demás y, por supuesto, con el 23, reconoce el derecho de asociarse libremente con diversidad de fines, entre ellos los políticos.

Derechos politicos, proceso electoral y partidos políticos, convergen entonces en inescindible unidad para la propuesta.

Su incorporación al plexo de derechos fundamentales en el sistema interamericano del Pacto de San José de Costa Rica se nos hace clara. 
Éste es el primer punto de arranque. Lo dejamos establecido casi dogmáticamente para obviar mayores explicaciones.

De inmediato tenemos que colacionar los ya citados artículos 8 y 25. El 25 establece el derecho de toda persona a un recurso sencillo y rápido o a cualquier otro recurso efectivo de tipo judicial, para ampararse contra actos violatorios de sus derechos fundamentales reconocidos en la Convención (además de su derecho interno). Aquí hay un punto de apoyo para considerar viable y debida la justiciabilidad de las cuestiones electorales que comprometen derechos políticos del artículo 23 y los que les son conexos en relación con los partidos.

Por su lado, el artículo 8, acápite 1, contempla el derecho de toda persona a ser oída, con las debidas garantías y dentro de plazo razonable, por un juez o tribunal competente, independiente e imparcial, y establecido con anterioridad por la Ley, para la determinación de sus derechos y obligaciones. Se mencionan los de orden civil, laboral, fiscal, y se añade "o de cualquier otra índole». En esta última referencia encuadran los aludidos derechos de índole política, que como ya vimos están contenidos en el Pacto, y vinculados con todo lo que atañe a los partidos como derivación del derecho de libre asociación del artículo 16.

Este somero repaso ofrece fundamento bastante para comprender que el espectro plúrimo de las cuestiones electorales no evade la justiciabilidad ni se retrae al control jurisdiccional.

Pero adviene una incorporación corroborante. En efecto, en las cláusulas del artículo 29 sobre interpretación del Pacto se prescribe como regla hermenéutica que ninguna disposición del mismo puede ser interpretada como excluyendo o limitando el efecto que pueda producir la Declaración Americana de Derechos y Deberes del Hombre:

Pues bien, en esta Declaración el artículo XX prevé el derecho de sufragio; el XVIII, el derecho de justicia, y el XXII, el derecho de asociación. De tal modo, la remisión a la mentada Declaración como otra fuente internacional de derechos y garantías nos refuerza en la misma idea que presentamos como tesis: la justiciabilidad y el control jurisdiccional de las cuestiones electorales.

Nos resta indagar si la propuesta sólo reviste el carácter de una insinuación u orientación para los Estados que son parte en el Pacto de San José de Costa Rica, o si tiene el vigor de una obligación asumida al haberlo hecho objeto de ratificación o adhesión.

El artículo 1, acápite 1 -tal como lo ha interpretado la Corte Interamericana de Derechos Humanos y conforme a nuestra personal opinión-, obliga automática y directamente a los Estados parte en la Convención a respetar los derechos y libertades reconocidos en ella y a garantizar su libre y pleno ejercicio. Ello significa que el Pacto inviste directamente de 
la titularidad de sus derechos, libertades y garantías en el derecho interno a toda persona que esté sujeta a la jurisdicción de un Estado parte, lo que significa que el deber y la responsabilidad internacionales de tal Estado juega como complemento de reforzamiento de su obligación interna.

Nada de lo afirmado precedentemente pierde fuerza por el hecho de que el artículo 2 prevea que si el ejercicio de los derechos y libertades mencionados en el artículo 1 no estuviere ya garantizado en un Estado parte, éste se compromete a reajustar su derecho interno en lo que fuere necesario para hacer efectivos tales derechos.

Esta cláusula no tiene, en modo alguno -y así surge también de la doctrina de la Corte Interamericana-, el alcance de convertir a la totalidad de las normas del Pacto en programáticas. Por consecuencia, no significa que quede librado al criterio y a la discrecionalidad de los Estados parte adoptar o no las medidas necesarias para conferir efectividad a los derechos, libertades y garantías contenidos en el plexo normativo del mismo Pacto.

En suma, el Pacto irroga directamente el deber interno e internacional de cumplimiento efectivo. Tal deber se desdobla, a nuestro entender, de la siguiente manera:

a) Las cláusulas operativas (o self-executing) no requieren de ninguna ley ni medidas internas para su funcionamiento, y dejan expedito el ejercicio de los derechos, libertades y garantias en ellas reconocidos;

b) las cláusulas programáticas obligan a adoptar las medidas de derecho interno (legislativas o de otro carácter) que sean necesarias para hacer efectivos los aludidos derechos, libertades y garantías;

c) hay que partir de la presunción de operatividad de las cláusulas del Pacto, a menos que de las mismas surja indudablemente que son de carácter programático, caso en el cual existe la obligación aludida en el anterior inciso b).

A esta altura de nuestro discurso argumental se nos vuelve fácil sostener que en la comprensión valorativa y coherente de los artículos 8 , 23,25 , y 29 , su conjunto armonizado e interrelacionado conduce a verificar que el Pacto impone a los Estados parte de él a garantizar la judiciabilidad y el control jurisdiccional suficiente de las cuestiones electorales en las que se comprometen derechos políticos, y los que les son conexos en materia de partidos políticos. 
Las disposiciones que hemos colocado como fundamento tienen, a nuestro juicio, naturaleza operativa, de modo que no solamente no hace falta ninguna norma interna o medida de otro carácter para que funcionen, para que se apliquen, y para que se hagan valer, sino que en el caso hipótetico de quề en algún Estado parte todavia no se hayan hecho efectivos los derechos, libertades y garantías emergentes de las mentadas disposiciones, hay obligación de efectivizarlos.

Cuando aludimos a deber o a obligación, reiteramos que enfrentamos a uno y a otra tanto en el Derecho Internacional cuanto en el interno. Y no vale excepción alguna porque, como mínimo, damos por ciertas tres cosas:

a) Que los derechos humanos -y los aqui referidos lo son-forman parte del ius cogens;

b) que también forman parte de los principios generales del Derecho Internacional Público y del Derecho Internacional de los Derechos Humanos;

c) que el Derecho interno no exime del deber de cumplir un tratado en el que el Estado se ha hecho parte.

Como conclusión de la tesis reseñada, conviene recordar que si es verdad todo cuanto acabamos de desarrollar en torno del Pacto de Costa Rica, las cuestiones electorales conexas con los derechos políticos y los partidos, ya no pertenecen a la jurisdicción exclusiva y reservada de los Estados parte, porque aun cuando siguen incluidas en su jurisdicción interna, forman parte también de la jurisdicción internacional concurrente o compartida con la jurisdicción interna. Deben resolverse en la jurisdicción interna, pero no de cualquier modo ni a criterio exclusivo y unilateral de cada Estado, sino de manera compatible y afín con lo que el Pacto de San José prescribe obligatoriamente con la fuerza de un tratado internacional. Por eso acabamos de expresar que no estamos ante materia exclusiva de la jurisdicción interna reservada, sino de materia que, sin retraerse a la jurisdicción interna, no le es exclusiva porque el Derecho Internacional le ha marcado cánones indisponibles al haber asumido también para la jurisdicción internacional la misma materia. 